\title{
Fifth Meeting on Bone Quality: \\ Bone Fracture Healing and Strengthening
}

\section{France, June 2010}

\author{
Coordinators: \\ C.L. Benhamou, C. Roux
}

The publication of the proceedings of the 5th Bone

Quality Seminar 2010 has been made possible through an educational grant from Servier

Osteoporosis International

黛 Springer 